\title{
Avaliação de Extensões de Marca: uma pesquisa experimental no setor de serviços
}

\section{Brand Extension Evaluation: an experimental research study in the service sector}

\section{Evaluación de extensiones de marca: un estudio experimental en el sector servicios}

\author{
Renato Ferreira Pimenta ${ }^{1}$ \\ Evandro Luiz Lopes ${ }^{2}$ \\ Dirceu da Silva ${ }^{3}$ \\ Francisco Antonio Serralvo ${ }^{4}$
}

Recebido em 07 de janeiro de 2013 / Aprovado em 30 de junho de 2014

Editor Responsável: João Maurício Gama Boaventura, Dr.

Processo de avaliação: Double Blind Review

\section{RESUMO}

Este estudo tratou da análise dos efeitos, na avaliação dos consumidores, de diferentes nomes de marcas (arbitrária, descritiva e sugestiva), da similaridade (alta versus baixa) e da qualidade percebidas em relação a extensóes de marcas em serviços. Foram realizados dois experimentos que envolveram 1.338 respondentes. No Experimento 1, por meio da análise de variância multivariada (Manova), verificaram-se efeitos significantes dos nomes de marcas e da similaridade na atitude e na intenção de uso dos consumidores. No Experimento 2 , adicionada a manipulação da qualidade percebida, verificou-se a transferência desta para o serviço estendido e sua sobreposição aos efeitos da similaridade e dos nomes de marcas nas extensões, indicando que esse construto é mais relevante na avaliação das extensôes de marcas em serviço quando os nomes das marcas não são reconhecidos pelos consumidores.

Palavras-chave: Extensão de marcas. Serviços. Qualidade em serviços. Similaridade percebida.

\begin{abstract}
This study analyzed the effects, in consumers' evaluations, of different brand names (arbitrary, descriptive, and suggestive), of perceived similarities (high vs. low) and of perceived
\end{abstract}

1. Doutorando em Marketing pela Universidade Nove de Julho (UNINOVE). [pimentamkt@gmail.com]

2. Doutor em Marketing e Professor do Programa de Mestrado e Doutorado em Administração da Universidade Nove de Julho (UNINOVE). [elldijo@uol.com.br]

3. Doutor em Educação (Avaliação e Cognição) pela Universidade de São Paulo (USP). Professor do Programa de Pós-Graduação em Administração da Universidade Nove de Julho e da Universidade Estadual de Campinas (Unicamp). [dirceus@uninove.br]

4. Doutor em Ciências Sociais e Professor Titular pela Pontifícia Universidade Católica de São Paulo (PUC). [serralvo@pucsp.br] Endereço dos autores: Universidade Nove de Julho - Av. Francisco Matarazzo, 612, Cep. 05001-100 - Sáo Paulo - SP - Brasil 
quality regarding brand extension in services. We implemented two experiments involving 1,338 respondents. In Experiment 1, by means of MANOVA, we managed to detect significant effects of brand names and of similarities in Attitude and Intention to Use of consumers. In Experiment 2, we added manipulation of perceived quality to the sample. We identified transfer of perceived quality to extended service, and that perceived quality overweighed effects of similarity and brand names in extensions, which indicates that perceived quality is more relevant in evaluation of brand extension in service when brand names are not recognized by consumers.

Keywords: Brand extension. Services. Service quality. Perceived similarity.

\section{RESUMEN}

Este estudio trata del análisis de los efectos en la evaluación de los consumidores de distintos nombres de marcas (arbitraria, descriptiva y sugestiva), de la similitud percibida en relación a extensiones de marcas en servicio. Se realizaron dos experimentos que abarcaron 1.338 encuestados. En el Experimento 1, mediante el análisis de MANOVA, se han verificado efectos significativos de los nombres de marcas y la similitud en la actitud y en la intención de uso de los consumidores. En el Experimento 2, sumada a la manipulación de la calidad percibida, se ha verificado la transferencia de esta para el servicio extendido y su sobreposición a los efectos de la similitud y de los nombres de marcas en las extensiones, indicando que este constructo es más relevante en la evaluación de las extensiones de marcas en servicio, cuando los nombres de las marcas no son reconocidos por los consumidores.

Palabras clave: Extensión de marca. Servicios. Calidad de servicios. Similitud percibida.

\section{INTRODUÇÃO}

Nota-se que a grande utilização da extensão de marca se dá, principalmente, em razão dos pontos positivos que a marca-máe pode oferecer a sua extensão, podendo tornar produtos ou serviços mais atrativos para consumidores (AAKER, KELLER, 1990; KELLER, 2003) e despertar a percepção de vantagens para a cadeia de fornecimento e distribuição envolvida, com possíveis reduções de custos e maiores chances de sucesso, além da possibilidade de garantir a manutenção do brand equity (MORRIN, 1999).

O tema extensão de marca tem sido bastante abordado no que concerne ao setor de bens (AAKER, KELLER, 1990; KELLER, 2003; BATRA, LENK, WEDEL, 2010). Apesar disso, diversos autores indicam que existe carência de pesquisas relativas ao tema aplicado ao setor de serviços (MARTÍNEZ, PINA, 2005; HERNANDEZ et al., 2011).

Dada a incipiência de estudos sobre as extensôes de marca no setor de serviços (VAN RIEL, LEMMINK, OUWERSLOOT, 2001), o qual atualmente representa a maior parte da economia de diversos países, incluindo o Brasil, e observada a importância e a popularidade da estratégia de extensão de marca, torna-se fundamental saber como o consumidor avalia a extensão no contexto de serviços (VÖLCKNER, SATTLER, 2006). Diante do exposto, este estudo tem o objetivo de analisar o efeito de diferentes tipos de nome de marca (arbitrária, descritiva e sugestiva) em diferentes níveis de percepção de similaridade entre os serviços (alta similaridade versus baixa similaridade) e diferentes níveis de percepção de qualidade dos serviços (alta qualidade versus baixa qualidade) da marca mãe, nas avaliações dos consumidores, no contexto de extensão de marcas. Realizaram-se, para tanto, dois experimentos de campo, nos quais foram simuladas situações de extensão de marcas em serviços com diferentes níveis de similaridade percebida pelos participantes.

Os resultados dos experimentos realizados estão apresentados nesse artigo, o qual está estruturado da seguinte forma: após esta breve introdução, a segunda seção apresenta a revisão da literatura na qual são evidenciados os principais conceitos teóricos sobre extensão de marcas e suas estratégias. Em seguida, realiza-se a formulação das hipóteses que serão testadas na fase empírica 
da pesquisa. Na terceira e na quarta seçáo, apresenta-se a concepçáo dos experimentos realizados e os resultados obtidos. Logo após, na quinta seção, há a discussão dos resultados e a apresentação das contribuiçôes acadêmicas e gerências, além de sugestôes de direcionamento para estudos futuros.

\section{REVISÃO DA LITERATURA}

Serão apresentados a seguir os principais conceitos que deram suporte à pesquisa e as hipóteses geradas a partir da literatura.

\section{I Marcas e extensão de marcas}

O uso de marcas existe há milênios, sendo sua principal finalidade diferenciar bens e serviços de um fabricante ou prestador de serviços dos demais. Segundo a American Marketing Association (2014), uma marca pode ser definida como um nome, termo, símbolo, desenho ou uma combinação desses elementos, usados para identificar bens e serviços de um dado fornecedor.

A extensão de marca ocorre quando uma determinada marca é inserida em produtos ou serviços de linhas e/ou categorias diferentes daquela à qual pertence atualmente e pode ser considerada um artifício utilizado pelas empresas quando elas já contam com uma marca aceita no mercado (AAKER, 1998; KELLER, MACHADO, 2006; OLIVEIRA, MATTAR, 2001; NEERAKKAL, 2011). Um exemplo dessa estratégia de branding nos foi dado pela Nestlé, quando utilizou a marca Alpino, originalmente de um chocolate em barra, no lançamento de um sorvete.

Desde o estudo de Aaker e Keller (1990), a estratégia de extensão de marca começou a se intensificar, principalmente pelos pontos vantajosos que pode proporcionar, mas também chamou a atenção para os riscos que podem incorrer nesse tipo de ação (OLIVEIRA, MATTAR, 2001). Como vantagem, observa-se que a imagem de marca bem conhecida e bem apreciada cria nos consumidores determinadas expectativas, as quais são inferidas na extensão de marca, melhorando as associaçóes positivas percebidas e, em consequência, a imagem da marca. Ainda na mesma linha de pensamento, pode-se alcançar a diminuição da percepção de risco pelos consumidores (KELLER, AAKER, 1992; MARTÍNEZ, PINA, 2005; KELLER, MACHADO, 2006; NEERAKKAL, 2011) e o aumento da eficiência promocional (SULLIVAN, 1992; SMITH, 1992; SMITH, PARK, 1992), além de outros tipos de associação relativas às extensôes de marcas feitas adequadamente, que geram percepçóes favoráveis quanto à credibilidade da empresa dona da extensão (KELLER, AAKER, 1992; MARTÍNEZ, PINA, 2005). Por outro lado, o produto que recebeu a extensão de marca poderia ser prejudicado caso ocorresse algum problema com o produto da marca já estabelecida (AAKER, 1998).

\subsection{Estratégias de naming}

O nome de marca é uma escolha fundamental, sendo muitas vezes a tomada de decisão mais difícil e aquela que pode traçar diretrizes para o sucesso ou insucesso do bem ou serviço (KELLER, HECKLER, HOUSTON, 1998). Este estudo considerou alguns tipos de nomes de marcas (KELLER, MACHADO, 2006) que podem ser classificados como descritivos, sugestivos, compostos, clássicos, arbitrários e fantasia. Optou-se pela utilização dos tipos de nome de marca a) descritivo, que descreve literalmente a função do serviço ou atividade da empresa; b) sugestivo, que sugere um benefício ou uma função do serviço; e c) arbitrário, que faz uso de palavras reais sem nenhum vínculo com o serviço ou atividade da empresa, por serem os mais usuais (KELLER, HECKLER, HOUSTON, 1998).

\subsection{A similaridade e a qualidade em extensóes de marcas em serviços}

A literatura indica a constituição da similaridade no contexto da extensão de marca. Para Aaker e Keller (1990), a similaridade é dada por três atributos: a complementaridade, a substituibilidade e a transferibilidade. A complementaridade está associada à possibilidade de utilizaçáo de produtos (ou serviços) em conjunto 
ou simultaneamente (por exemplo, gasolina e aditivos ou alisamento e pintura dos cabelos). A substituibilidade é associada à possibilidade de escolha entre um ou outro produto ou serviço (por exemplo, a escolha entre um doce ou um sorvete para sobremesa). A transferibilidade, por sua vez, é identificada quando um provedor utiliza a mesma estrutura para oferecer dois produtos (ou serviços) diferentes. Por exemplo, uma fábrica que pode produzir copos e porta-retratos simultaneamente, pois utiliza a mesma matéria-prima (vidro) ou um hotel que oferece acomodaçóes para seus hóspedes e também é utilizado como local para festas de casamento.

Um estudo desenvolvido por Hernandez et al. (2011), com o objetivo de avaliar o efeito da qualidade percebida da marca-mãe (definida pelo autor como a percepçáo dos consumidores acerca da qualidade ou superioridade da marca em relação às marcas concorrentes) e da similaridade percebida (definida como a percepção acerca da similaridade entre o serviço original e aquele que recebeu a extensão de marca) sobre as avaliaçóes de extensôes de marcas corporativas em serviços, encontrou resultados que sugerem que a qualidade percebida da marca-mãe apresenta papel fundamental na avaliação de extensões de marcas corporativas em serviços. Trazendo evidências contraditórias a estudos anteriores (PINA et al., 2006; VÖLCKNER et al., 2010) demonstraram que a qualidade percebida da marca-mãe é significativamente mais importante que a similaridade percebida no contexto de serviços.

Lopes e Hernandez (2010), diante de várias questôes acerca das estratégias de extensão de marcas, realizaram um estudo com o objetivo de verificar os efeitos de diferentes tipos de nome de marca na avaliação dos consumidores. Após a análise dos dados oriundos de uma amostra composta por 170 estudantes universitários, os autores concluíram que: a) o nome de marca carregado de significado apresenta melhor avaliação que o nome de marca inventado, quando a extensão da marca ocorrer para um formato bastante similar ao que deu origem à extensão; b) o nome de marca inventado apresenta melhor avaliaçáo que o nome carregado de significado, quando a extensão da marca ocorrer para um formato pouco similar ao que deu origem à extensão; c) o nome de marca próprio apresenta melhor avaliação que o nome de marca inventado, quando a extensão da marca ocorrer para um formato similar ao que deu origem à extensão; d) o nome de marca próprio apresenta melhor avaliação que o nome de marca carregado de significado, quando a extensão da marca ocorrer para um formato pouco similar ao que deu origem à extensão.

A qualidade percebida e a similaridade entre a marca-mãe e a marca estendida (respectivamente MM e ME, deste ponto em diante) são as principais determinantes de uma boa avaliação de extensôes de marcas (BOTTOMLEY, HOLDEN, 2001; VÖLCKNER, SATTLER, 2006). Pesquisas têm apresentado, no entanto, diferentes efeitos dessas duas variáveis na avaliação de extensôes de marcas em serviços. Alguns estudos encontraram efeitos altamente significantes da similaridade em extensões de marcas (RUYTER, WETZELS, 2000; LEI et al., 2004; MARTINEZ, PINA, 2005; VAN RIEL, OUWERSLOOT, 2005), ao passo que outros apontaram que a qualidade percebida da MM apresentou um efeito mais significante que o efeito da similaridade nas extensões de marcas em serviços (VÖLCKNER et al., 2010; HERNANDEZ et al., 2011).

Apesar de a literatura não apontar para um modelo específico para mensuração da qualidade em serviços (CRONIN, TAYLOR, 1992; LEE, LEE, YOO, 2000), é possível observar que a maioria dos modelos faz uso das cinco dimensôes gerais (Aspectos Tangíveis, Confiabilidade, Presteza, Segurança e Empatia) do Servqual (PARASURAMAN, ZEITHAML, BERRY, 1990). Pela necessidade da criação, neste estudo, das evidências de qualidade em serviços, optou-se pela utilização das cinco dimensôes do Servqual, pois este é o modelo mais utilizado e replicado para mensuração da qualidade percebida em serviços em todo o mundo (LOPES, HENANDEZ, NOHARA, 2009).

\subsection{Formulação das hipóteses}

O nome da marca é uma escolha fundamental. Costuma-se utilizar, na escolha do nome, 
termos que sugiram a categoria. Deve-se destacar, porém, que, quando o nome de marca descreve ou sugere muito a categoria, pode-se tornar restritivo quanto à extensão de marca (KELLER, HECKLER, HAUSTON, 1998).

Comumente, um maior grau de similaridade implica uma melhor avaliação de qualquer tipo de extensão (AAKER, KELLER, 1990; BOUSH, LOKEN, 1991; RUYTER, WETZELS, 2000). Por outro lado, os consumidores podem dar maior atenção para os atributos da extensão se os benefícios dela não oferecerem similaridade com a MM, independentemente da força da marca (BOUSH, LOKEN, 1991). A influência da similaridade percebida na avaliação de extensôes já foi analisada sob perspectivas de produtos tangíveis (AAKER, KELLER, 1990; BOUSH, LOKEN, 1991), de serviços (RUYTER, WETZELS, 2000; ALLARD, VAN RIEL, OWERSLOOT, 2005; MARTÍNEZ, PINA, 2005) e de ambas as visôes (VAN RIEL, LEMMINK, OUWERSLOOT, 2001). Por conseguinte, esta pesquisa propõe as primeiras hipóteses a serem testadas.

$\mathrm{H} 1$ = A extensão de marca com nome descritivo será mais bem avaliada que a extensão de marca com nome arbitrário quando a similaridade percebida do serviço da MM e da ME for alta (versus baixa).

H2 = A extensão de marca com nome sugestivo será mais bem avaliada que a extensão de marca com nome arbitrário quando a similaridade percebida do serviço da MM e da ME for alta (versus baixa).

H3 = A extensão de marca com nome sugestivo será mais bem avaliada que a extensão de marca com nome descritivo quando a similaridade percebida do serviço da MM e da ME for alta (versus baixa).

Tanto para marcas de serviços como para as de produtos existe a influência direta da qualidade percebida na avaliação de extensôes (SUNDIE, BRODIE, 1993; VAN RIEL, LEMMINK, OUWERSLOOT, 2001; ALLARD, VAN RIEL,
OUWERSLOOT, 2005; MARTÍNEZ, PINA, 2005; HERNANDEZ et al., 2011). A percepção de maior qualidade na marca principal pode propiciar uma melhor avaliação da extensão: diante disso, propóe-se testar a seguinte hipótese:

H4 = A extensão de marca com nome descritivo será mais bem avaliada que a extensão de marca com nome arbitrário quando a similaridade e a qualidade percebidas no serviço entre a $\mathrm{MM}$ e a $\mathrm{ME}$ forem altas (versus baixas).

$\mathrm{Na}$ atividade de marketing, o uso de marcas vai além do objetivo de identificar as empresas. As marcas diferenciam produtos e serviços e agregam valor aos mesmos, contribuindo para a obtenção de vantagem competitiva (NEERAKKAL, 2011). Além disso, ao adquirir um produto ou consumir um serviço, o consumidor não compra apenas um bem, mas sim todo o conjunto simbólico de valores e atributos da marca (LOPES; HERNANDEZ, 2010). O nome de marca sugestivo pode proporcionar ao consumidor a percepçáo de determinados benefícios, mas, por outro lado, pode ser restritivo no caso da utilização da marca em uma categoria que apresente pouca similaridade com a categoria da MM (KELLER; HEKLER; HOUSTON, 1998). Portanto, formula-se:

H5 = A extensão de marca com nome sugestivo será menos bem avaliada que a extensão de marca com nome arbitrário quando a similaridade e a qualidade percebidas no serviço entre a $\mathrm{MM}$ e a $\mathrm{ME}$ forem baixas (versus altas).

Keller (2003) afirma que se uma marca criar associaçôes positivas poderá garantir certo destaque no mercado, ou seja, uma marca que sugira benefícios, transferibilidade e complementaridade (AAKER, KELLER, 1990), além de propiciar bons sentimentos na percepção do consumidor a respeito da qualidade, terá maior chance de sucesso. Diante disso, formula-se a seguinte hipótese: 
H6 = A extensão de marca com nome sugestivo será mais bem avaliada que a extensão de marca com nome descritivo quando a similaridade e a qualidade percebidas no serviço entre a MM e a ME forem altas (versus baixas).

A literatura de extensão de marca já apontou que os principais determinantes de uma boa avaliação de extensôes de marcas são a similaridade percebida e a qualidade percebida da MM (BOTTOMLEY, HOLDEN, 2001; VÖLCKNER, SATTLER, 2006). Pesquisas têm apresentado, no entanto, resultados contraditórios sobre os efeitos dessas duas variáveis na avaliação de extensões de marcas em serviços. Ruyter e Wetzels (2000), Lei et al.,(2004) e Van Riel e Ouwersloot (2005) encontraram efeitos significantes da similaridade nas avaliações das extensóes de marcas. Völckner et al. (2010) e Hernandez et al. (2011) apontaram que a qualidade percebida da MM apresentou um efeito mais significante que o efeito da similaridade nas extensóes de marcas em serviços. Provavelmente, esses resultados contraditórios se justificam pela utilização de desenhos de pesquisa diferentes. Com base nisso, propóe-se testar as seguintes hipóteses:

H7 = A extensão de marca com nome descritivo será menos bem avaliada que a extensão de marca com nome sugestivo quando a similaridade percebida no serviço entre a MM e a ME for baixa e a qualidade percebida no serviço entre a MM e a ME for alta.

H8 = A extensão de marca com nome sugestivo será mais bem avaliada que a extensão de marca com nome arbitrário quando a similaridade percebida no serviço entre a MM e a ME for alta e a qualidade percebida no serviço entre a MM e a ME for baixa.

H9 = A extensão de marca com nome arbitrário será mais bem avaliada que a extensão de marca com nome descritivo quando a similaridade percebida no serviço entre a MM e a ME for baixa e a qualidade percebida no serviço entre a MM e a ME for alta.

\section{EXPERIMENTO 1}

O Experimento 1 teve como objetivo testar os efeitos de diferentes tipos de nomes de marcas e da similaridade percebida na avaliação dos consumidores em relação às extensóes de marcas, sendo um formato $3 \times 2: 3$ tipos de nomes de marcas [descritivo, sugestivo e arbitrário] x 2 similaridade [alta versus baixa]. Neste experimento, foram testadas as hipóteses $\mathrm{H} 1, \mathrm{H} 2$ e H3.

\section{I Desenvolvimento dos estímulos do experimento 1}

Para o desenvolvimento dos estímulos, foram realizados processos de brainstorming, seguidos de classificações com utilização de formulários de pesquisa. Tanto os processos de brainstorming como os de classificação foram realizados com estudantes universitários do curso de Administração de uma grande universidade privada. Esses sujeitos, além de serem estudantes, possuem atividade profissional remunerada, o que os caracteriza como responsáveis por suas decisôes de compra.

O primeiro processo de brainstorming envolveu um grupo de estudantes $\left(n=6 ; M_{\text {idade }}=\right.$ 27; $\mathrm{dp}=3,14)$ e teve a finalidade de construir uma lista de tipos de serviços que teriam suas marcas estendidas. A lista gerada pelo grupo continha 47 tipos de serviços diferentes.

A lista idealizada foi submetida a um novo grupo de estudantes $\left(\mathrm{n}=40 ; \mathrm{M}_{\text {idade }}=31 ; \mathrm{dp}=\right.$ 6,77), que classificou os tipos de serviços listados quanto à frequência de uso em uma escala de dez pontos, sendo 1 - nunca utilizo este serviço e 10 - sempre utilizo este serviço. Para a realização do Experimento 1, considerou-se apenas o serviço que apresentou a maior média [Supermercado $(M=9,30 ; d p=1,30)]$. 
Selecionado o formato de serviço para o Experimento 1, um novo grupo de estudantes $\left(\mathrm{n}=6 ; \mathrm{M}_{\text {idade }}=25 ; \mathrm{dp}=2,31\right)$, por meio de mais um processo de brainstorming, idealizou uma lista de nomes de marca descritivas $(n=12)$ para o serviço selecionado. Essa lista foi submetida a outro grupo de estudantes $\left(n=40 ; M_{\text {idade }}=28\right.$; $\mathrm{dp}=5,59)$, que a classificou em uma escala de dez pontos, sendo 1 - este nome de marca não descreve o serviço de um supermercado e 10 - este nome de marca descreve totalmente o serviço de um supermercado. A marca Armazém ( $M=5,98$; $\mathrm{dp}=3,53)$ obteve a maior média.

O mesmo procedimento foi adotado para nome de marca sugestiva; portanto, um novo grupo de estudantes universitários $\left(n=6 ; M_{\text {idade }}\right.$ $=23 ; \mathrm{dp}=1,96)$, por meio de mais um processo de brainstorming, idealizou uma lista de nomes de marcas sugestivas $(n=16)$. Essa lista foi submetida a outro grupo de estudantes universitários $\left(\mathrm{n}=40 ; \mathrm{M}_{\text {idade }}=28 ; \mathrm{dp}=7,68\right)$, que a classificou em uma escala de dez pontos, sendo 1 - este nome de marca não sugere benefícios do serviço de um supermercado e 10 - este nome de marca certamente sugere benefícios do serviço de um supermercado. A marca Leve Mais $(M=5,95$; $\mathrm{dp}=3,12)$ apresentou-se como a mais adequada.

Para a escolha do nome de marca arbitrária, foram utilizados os recursos do website namestation.com, específico para a geração de nomes e domínios em diversos idiomas. Foram gerados 15 nomes de marca arbitrária e um grupo de estudantes $\left(\mathrm{n}=40 ; \mathrm{M}_{\text {idade }}=26 ; \mathrm{dp}=5,66\right)$ os avaliou em uma escala de dez pontos, sendo 1 - este nome de marca é muito ruim para um supermercado e 10 - este nome de marca certamente é muito bom para um supermercado. A marca Ambra $(M=5,43 ; \mathrm{dp}=3,10)$ apresentou maior média.

Para manipular a similaridade do serviço estendido em relação ao serviço de origem, foi realizado mais um processo de brainstorming com um grupo de estudantes $\left(\mathrm{n}=6 ; \mathrm{M}_{\text {idade }}=24 ; \mathrm{dp}=\right.$ $2,34)$, que idealizou uma lista de tipos de serviços $(\mathrm{n}=36)$. Essa lista foi submetida a outro grupo de estudantes $\left(n=40 ; M_{\text {idade }}=31 ; d p=6,28\right)$, que classificou os tipos de serviços listados em relação à similaridade a um Supermercado utilizando uma escala de dez pontos, sendo 1 - nada similar e 10 - muito similar. Os sujeitos que participaram da classificação dos serviços quanto à similaridade foram apresentados às mesmas medidas de similaridade utilizadas por Aaker e Keller (1990), ou seja, os sujeitos receberem informaçôes e orientaçôes sobre complementaridade, substituibilidade e transferibilidade.

O serviço Restaurante foi considerado o mais adequado para representar alta similaridade e o serviço de Agência de Turismo, o mais adequado para ser o serviço de baixa similaridade perante um Supermercado, conforme resultado do teste $t$ de Student para amostras pareadas $\left(\mathrm{M}_{\text {Restaurante }}=7,31 ; \mathrm{dp}=2,36 \mathrm{e} \mathrm{M}_{\text {Agência de Turismo }}=3,73\right.$; $\mathrm{dp}=2,71 ; \mathrm{t}(38)=6,903 ; \mathrm{p}<0,01 \%)$ que apontou diferença significante da similaridade percebida entre os formatos.

\subsection{Amostra e procedimentos de controle experimento 1}

A amostra foi composta por consumidores de serviços e colaboradores de uma rede varejista de materiais de construção que possui várias lojas no estado de São Paulo. No total, para realização da pesquisa, optou-se por aplicar os questionários em nove lojas diferentes. A distribuição dos questionários para as lojas e para os respondentes foi feita de maneira aleatória; contudo, como a seleção deu-se entre os frequentadores das lojas em determinado dia, a amostra foi classificada como não probabilística por conveniência (FIELD, 2009).

A aplicação dos questionários, desenvolvidos no formato de formulários de autopreenchimento em papel foi feita por pesquisadores treinados por um dos autores deste artigo.

A amostra final do Experimento 1 contou com 279 respondentes e representou retorno de 93\% dos 300 questionários aplicados, sendo composta por 125 respondentes do sexo masculino $(44,8 \%)$ e 154 do sexo feminino $(55,2 \%)$, com idade média de 33 anos $(\mathrm{dp}=10,55)$. Foram descartados 21 questionários (7\% do total), que retornaram sem preenchimento ou com missing values. 


\subsection{Plano de análise dos dados do experimento 1}

Pelo fato de ser este estudo do tipo pesquisa experimental, utilizaram-se as técnicas de estatística descritiva de Análise Fatorial Exploratória (AFE) e de Análise de Variância Multivariada (Manova). Para tratamento dos dados, foi utilizado o software estatístico SPSS for Windows versão 15 .

\subsection{Instrumento de coleta de dados do experimento 1}

Os instrumentos de coleta de dados foram estruturados em três partes. Os formulários apresentaram poucas diferenças entre si, as quais, na primeira parte, foram decorrentes da manipulação das variáveis envolvidas. Utilizaram-se seis formulários contendo estímulos diferentes. O Apêndice 1 apresenta a operacionalização dessa manipulação.

$\mathrm{Na}$ segunda parte dos formulários, tratou-se da mensuração da avaliação das extensões de marca e da verificação da eficiência da manipulação dos estímulos, por meio de uma escala Likert de 7 pontos, sendo 1 - Discordo Totalmente e 7 Concordo Totalmente. Como em estudos experimentais anteriores (LOPES, HERNANDEZ, 2010; SHEERAN, HARRIS, EPTON, 2014), a avaliação foi mensurada por meio da atitude e da intençáo de uso do serviço de ME. Ao total foram utilizadas 12 afirmativas, sendo oito para mensurar a atitude e quatro para a intenção de uso (Apêndice 2), adaptadas de Lopes e Hernandez (2010). Para realizar a checagem do tipo de nome de marca, da similaridade e da qualidade percebida da MM, foram utilizadas três afirmativas, uma para cada variável (Apêndice 2). Vale ressaltar que foi realizado um pré-teste com um grupo de estudantes do curso de Administração $(\mathrm{n}=36)$ que ratificou a eficácia do instrumento de pesquisa e possibilitou pequenos ajustes. A terceira parte dos formulários solicitava dados categóricos aos respondentes.

\subsection{Resultados do experimento 1}

para verificar a eficiência da manipulação dos tipos de nomes de marca, realizou-se o teste Qui-Quadrado. O resultado do teste $(\chi 2=$ $112,637 / 12$ g.l.; $\mathrm{p}<0,01)$ indicou que os participantes identificaram a diferença entre as marcas sugestiva, descritiva e arbitrária. Da mesma forma, o teste $t$ de Student para amostras independentes apontou diferença significante na percepçáo dos respondentes na manipulação da similaridade ("A atividade de um(a) < Formato do Serviço de $M E>$ é certamente muito similar à atividade de um Supermercado" / $\mathrm{M}_{\text {Agência de Turismo }}=2,82$; $\mathrm{dp}=2,03$ e $\mathrm{M}_{\text {Restaurante }}=3,58 ; \mathrm{dp}=2,01 ; \mathrm{t}(271)=$ 3.097; $\mathrm{p}<0,01)$.

Realizada a verificação da manipulação dos estímulos, partiu-se para a verificação das afirmativas de avaliação. A AFE foi realizada com rotação oblíqua Oblimin (não ortogonal) (HAIR et al., 2005; FIELD, 2009). A adoção desse método de rotação justifica-se pelo fato de existir alta correlação teórica entre atitude e intenção de uso (AAKER, KELLER, 1990). A AFE utilizou a análise de componentes principais, apontando para a bidimensionalidade dos itens das variáveis dependentes. A consistência interna dos fatores foi adequada, pois identificou-se o índice de Alfa de Cronbach de 0,867 para os itens do fator atitude e 0,759 para os itens do fator intenção de uso (HAIR et al., 2005; FIELD, 2009). As cargas fatoriais foram adequadas, sendo superiores a 0,50 , e cargas cruzadas (entre fatores) inferiores a 0,30. Do mesmo modo, o $\operatorname{KMO}(0,916)$ apontou que a amostra é adequada para a utilização da técnica de AFE (HAIR et al., 2005; FIELD, 2009). A análise do teste de esfericidade de Bartlett não foi utilizada, assim como em outros estudos experimentais, pois o teste é muito sensível ao tamanho da amostra (FIELD, 2009).

Partiu-se, então, para a verificação por meio da Manova, para se observar os efeitos das estratégias de extensão de marcas na atitude e na intenção de uso dos respondentes. Como esperado, a Manova identificou efeito de interação entre Marca e Similaridade com atitude (F $(2,278)$ $=9,831 ; \mathrm{p}<0,01)$ e Marca e Similaridade com intenção de uso $(\mathrm{F}(2,278)=5,918 ; \mathrm{p}<0,01)$. Os resultados encontrados são demonstrados nos Gráficos 1 e 2. 
Verificou-se diferença significante na atitude em relação à extensão entre as marcas descritiva e arbitrária com manipulação de similaridade alta $\left(\mathrm{M}_{\text {Descritiva Similaridade Alta }}=5,10\right.$ e $\mathrm{M}_{\text {Arbitrária Similaridade Alta }}=$ $4,55 ; \mathrm{t}(93)=2,259 ; \mathrm{p}<0,05)$. Como se previa, a marca descritiva foi mais bem avaliada que a arbitrária, quando a similaridade percebida entre a MM e a extensão foi alta. Quando a similaridade percebida foi baixa, também se verificou diferença significante entre a avaliação das marcas $\left(\mathrm{M}_{\text {Descritiva }}\right.$ Similaridade Baixa $=4,33$ e $M_{\text {Arbitrária Similaridade Baixa }}=5,28$; $\mathrm{t}(88)=3,383 ; \mathrm{p}<0,01)$; contudo, na percepção de similaridade baixa, a marca arbitrária foi mais bem avaliada que a marca descritiva.

Da mesma maneira, a marca sugestiva apresentou diferença significante em relação à marca arbitrária quando a percepção da similaridade foi alta $\left(M_{\text {Sugestiva Similaridade Alta }}=5,29\right.$ e $M_{\text {Arbitrária }}$ Similaridade Alta $=4,55 ; \mathrm{t}(91)=3,040 ; \mathrm{p}<0,01)$ e baixa $\left(\mathrm{M}_{\text {Sugestiva Similaridade Baixa }}=4,77\right.$ e $\mathrm{M}_{\text {Arbitrária Similaridade Baixa }}$ $=5,28 ; \mathrm{t}(90)=1,949 ; \mathrm{p}<0,10)$. Observou-se que a marca sugestiva foi mais bem avaliada que a arbitrária quando a similaridade foi alta e menos bem avaliada que a marca arbitrária quando a percepção da similaridade foi baixa.

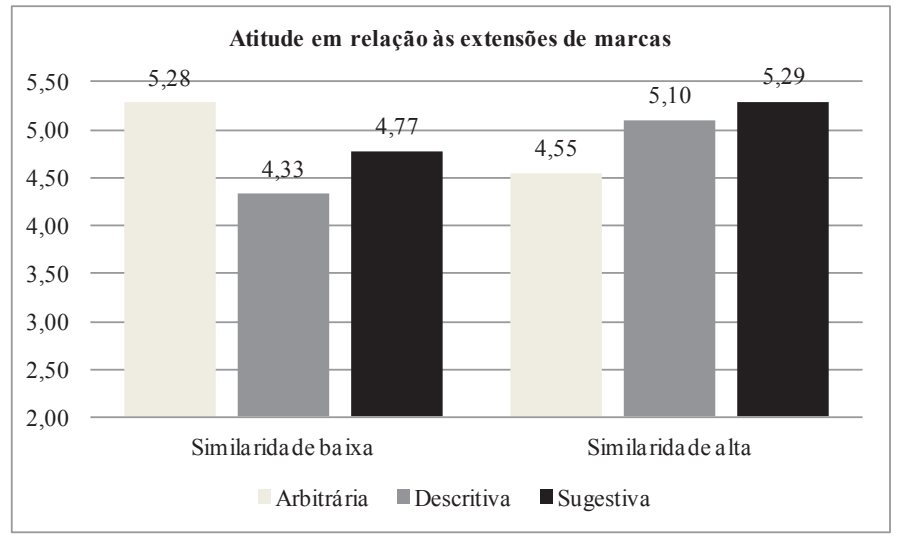

\begin{tabular}{lccc}
\hline Similaridade / Marca & Arbitrária & Descritiva & Sugestiva \\
\hline Baixa & 5,28 & 4,33 & 4,77 \\
Alta & 4,55 & 5,10 & 5,29 \\
\hline
\end{tabular}

GRÁFICO 1 - Experimento 1 - atitude em relação às extensôes

Fonte: Dados da pesqusia, elaborado pelos autores.

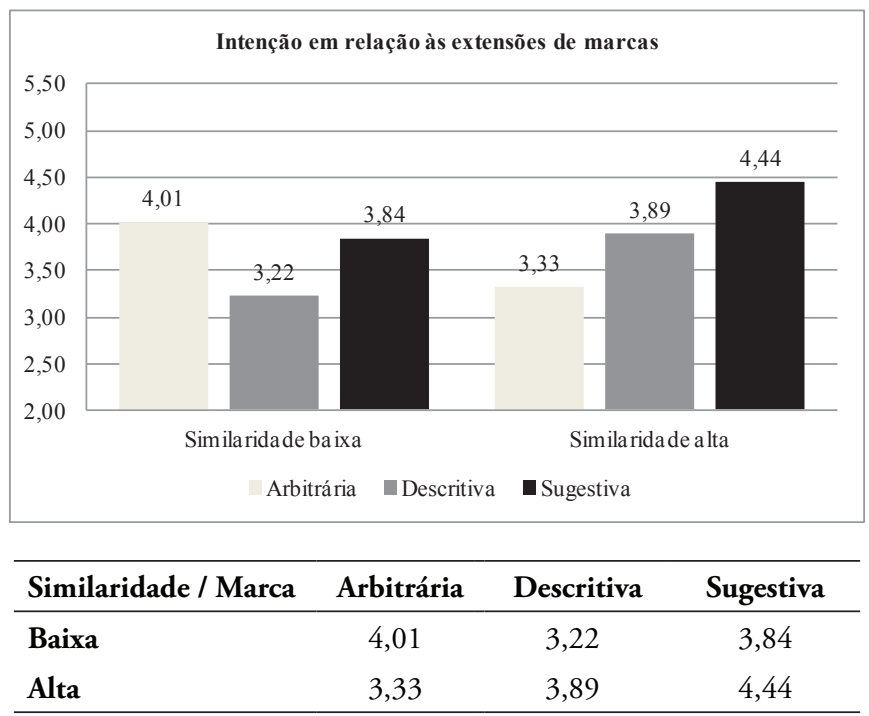

GRÁFICO 2 - Experimento 1 - Intenção em relação às extensões

Fonte: Dados da pesquisa, elaborado pelos autores. 
A atitude em relação à marca sugestiva comparada à marca descritiva com percepção de similaridade alta não apresentou diferença significante $\left(M_{\text {Sugestiva Similaridade Alta }}=5,29\right.$ e $M_{\text {Descritiva Similaridade }}$ Alta $=5,10 ; \mathrm{t}(86)=0,811 ; \mathrm{p}=\mathrm{n}$. s. $)$. Por outro lado, quando a percepção da similaridade foi baixa, a comparação entre as médias das marcas sugestiva e descritiva apresentou diferença significante $\left(\mathrm{M}_{\text {Sugestiva Similaridade Baixa }}=4,77\right.$ e $\mathrm{M}_{\text {Descritiva Similaridade Baixa }}$ $=4,33 ; \mathrm{t}(96)=1,684 ; \mathrm{p}<0,10)$, tendo sido $\mathrm{a}$ marca sugestiva mais bem avaliada que a marca descritiva.

Verificou-se também diferença significante na atitude em relação à extensão de marca arbitrária quando existe percepção de similaridade baixa (versus alta), entre o formato da MM e o formato estendido $\left(\mathrm{M}_{\text {Arbitrária Similaridade Alta }}=4,55\right.$ e $\mathrm{M}_{\text {Arbitrária }}$ Similaridade Baixa $=5,28 ; \mathrm{F}(1,90)=7,807 ; \mathrm{p}<0,01)$. A atitude é mais positiva quando uma marca arbitrária é estendida em um formato de similaridade baixa. Verificou-se, também, a existência de diferença significante na atitude em relação à extensão de marca descritiva $\left(\mathrm{M}_{\text {Descritiva Similaridade }}\right.$ Alta $=5,10$ e $M_{\text {Descritiva Similaridade Baixa }}=4,33 ; \mathrm{F}(1,91)$ $=8,592 ; \mathrm{p}<0,01)$ e de marca sugestiva $\left(\mathrm{M}_{\text {Sugestiva }}\right.$ Similaridade Alta $=5,29$ e $M_{\text {Sugestiva Similaridade Baixa }}=4,77$; $\mathrm{F}(1,91)=4,581 ; \mathrm{p}<0,05)$, quando feita a manipulação da similaridade (alta versus baixa), sendo que tanto a marca descritiva quanto a sugestiva foram mais bem avaliadas quando o formato da extensão apresentou similaridade alta em relação ao formato do serviço da MM.

Os resultados observados na intenção de uso dos respondentes quanto às extensóes de marcas foram bastante semelhantes aos observados na atitude. Observou-se diferença significante na intenção de uso em relação à extensão entre as marcas descritiva e arbitrária com percepção de alta similaridade $\left(\mathrm{M}_{\text {Descritiva Similaridade Alta }}=3,89\right.$ e $\mathrm{M}_{\text {Arbitrária }}$ Similaridade Alta $=3,33 ; \mathrm{t}(93)=2,212 ; \mathrm{p}<0,05)$. Do mesmo modo que ocorreu com a atitude, a marca descritiva foi mais bem avaliada que a arbitrária quando a similaridade percebida entre a $\mathrm{MM}$ e a extensão foi alta. Quando a similaridade percebida foi baixa, também se verificou diferença significante entre as marcas $\left(M_{\text {Descritiva Similaridade Baixa }}=3,22\right.$ e $\mathrm{M}_{\text {Arbitrária Similaridade Baixa }}=4,01 ; \mathrm{t}(88)=2,297$; $\mathrm{p}<0,05)$. Na percepção de similaridade baixa, no entanto, a marca arbitrária foi mais bem avaliada.

A marca sugestiva apresentou diferença significante em relação à marca arbitrária quando a percepção da similaridade foi alta $\left(\mathrm{M}_{\text {Sugestiva Simi- }}\right.$ laridade Alta $=4,44$ e $M_{\text {Arbitrária Similaridade Alta }}=3,33 ; \mathrm{t}(91)$ $=3,640 ; \mathrm{p}<0,01)$. Já na percepção de similaridade baixa $\left(\mathrm{M}_{\text {Sugestiva Similaridade Baixa }}=3,84\right.$ e $\mathrm{M}_{\text {Arbitrária Similaridade }}$ Baixa $=4,01 ; \mathrm{t}(90)=0,491 ; \mathrm{p}=$ n.s.), observou-se que não há diferença significante, resultado diferente do que se pretendia encontrar e do que ocorreu com a atitude.

A intenção de uso em relação à marca sugestiva comparada à marca descritiva com percepção de similaridade alta apresentou diferença significante $\left(\mathrm{M}_{\text {Sugestiva Similaridade Alta }}=4,44\right.$ e $\mathrm{M}_{\text {Descritiva }}$ Similaridade Alta $=3,89 ; \mathrm{t}(86)=1,766 ; \mathrm{p}<0,10)$.

Da mesma maneira se observou diferença significante quando a percepção da similaridade foi baixa entre as médias das marcas sugestiva e descritiva $\left(M_{\text {Sugestiva Similaridade Baixa }}=3,84\right.$ e $M_{\text {Descritiva }}$ Similaridade Baixa $=3,22 ; \mathrm{t}(88)=2,297 ; \mathrm{p}<0,05)$. A marca sugestiva foi mais bem avaliada que a descritiva tanto na percepção de similaridade baixa quanto na percepção de similaridade alta.

Identificou-se também diferença significante na intenção de uso em relação à extensão de marca arbitrária quando existe percepção de similaridade baixa (vs. alta), entre o formato do serviço da $\mathrm{MM}$ e o formato estendido $\left(\mathrm{M}_{\text {Arbitrária }}\right.$ Similaridade Alta $=3,33$ e $M_{\text {Arbitrária Similaridade Baixa }}=4,01$; $\mathrm{F}(1,90)=4,546 ; \mathrm{p}<0,05)$. A intençáo de uso também é mais positiva quando uma marca arbitrária é estendida em um formato de similaridade baixa. Verificou-se, ainda, a existência de diferença significante na intenção de uso em relação à extensão de marca descritiva $\left(M_{\text {Descritiva Similaridade Alta }}=3,89\right.$ e $M_{\text {Descritiva Similaridade Baixa }}=3,22 ; \mathrm{F}(1,91)=5,759$; $\mathrm{p}<0,05)$ e de marca sugestiva $\left(\mathrm{M}_{\text {Sugestiva Similaridade Alta }}=\right.$ 4,44 e $\mathrm{M}_{\text {Sugestiva Similaridade Baixa }}=3,84 ; \mathrm{F}(1,91)=3,190$; $\mathrm{p}<0,10)$ quando feita a manipulação da similaridade (alta versus baixa). Tanto a marca descritiva quanto a sugestiva foram mais bem avaliadas quando o formato da extensão foi de similaridade alta em relação ao formato do serviço da MM. 


\section{6 Discussáo dos resultados do experimento 1}

Os resultados encontrados ratificam estudos anteriores (KELLER, HECKLER, HOUSTON, 1998; KELLER, MACHADO, 2006), pois se observou que nomes de marca descritivos e sugestivos apresentaram melhor avaliação, tanto da atitude quanto da intenção de uso, quando a similaridade da extensão foi alta entre o formato estendido e o formato da MM. Um nome de marca que sugere benefícios de um serviço ou que o descreve pode facilitar a interpretação por parte do consumidor a respeito da marca (MOORE, LEHMANN, 1982; LOPES, HERNANDEZ, 2010).

Por outro lado, as pesquisas sobre extensões de marcas já verificaram que nomes de marcas que sugerem ou descrevem muito a categoria a que pertencem podem ser bastante restritivos quanto à extensão (KELLER, HECKLER, HOUSTON, 1998; KELLER, MACHADO, 2006; LOPES, HERNANDEZ, 2010). Os resultados do Experimento 1 confirmaram esses achados. Verificou-se que, quando a manipulação da similaridade do formato da extensão foi baixa em relação ao formato do serviço da MM, o nome de marca arbitrária foi mais bem avaliado que os nomes de marca descritiva e sugestiva. Assim, como foi observado nos resultados do Experimento 1, pode-se dizer que a $\mathrm{H} 1$ foi aceita completamente.

Os resultados aferidos apontam que não existiu diferença significante entre as marcas arbitrária e sugestiva apenas em relação à intenção de uso com manipulação de similaridade baixa. Apesar de se observar determinada tendência para a aceitação da Hipótese 2 ao se verificar as avaliaçôes atribuídas aos nomes de marca, tomou-se a decisão de rejeitá-la parcialmente.

Entre os nomes de marca descritiva e sugestiva, os resultados apontaram não existir diferença significante entre elas apenas em relação à atitude quando a manipulação da similaridade foi alta. Tal ocorrência pode ser resultante do fato de que tanto a marca descritiva quanto a marca sugestiva apresentam determinado significado para o consumidor, o que as torna bastante semelhantes no momento de realizar uma avaliação. No entanto, observou-se uma tendência para a aceitação da Hipótese 3, visto que no construto intenção de uso existiu diferença significante entre as referidas marcas. Mesmo assim, optou-se por rejeitar parcialmente a $\mathrm{H} 3$.

\section{EXPERIMENTO 2}

O Experimento 2 teve como objetivo medir os mesmos efeitos do Experimento 1 somada a manipulação da qualidade percebida. Teve formato $3 \times 2 \times 2$, sendo 3 tipos de nomes de marcas [descritivo, sugestivo e arbitrário] x 2 similaridade [alta versus baixa] x 2 qualidade percebida da MM [alta versus baixa]. O Experimento 2 e testou as hipóteses $\mathrm{H} 4$ a $\mathrm{H} 9$.

\section{I Desenvolvimento dos estímulos experimento 2}

O formato de serviço da MM utilizado neste segundo experimento também foi resultado do primeiro brainstorming realizado para o Experimento 1. Como descrito na seção 3.1, a lista gerada e posteriormente analisada identificou que o formato de serviço mais utilizado pelos estudantes universitários participantes era o Supermercado (utilizaçáo mensurado por meio da escala de dez pontos sendo 1 - nunca utilizo este serviço e 10 - sempre utilizo este serviço). $\mathrm{O}$ segundo formato mais utilizado foi o Posto de Combustíveis (M - 7,13; dp - 2,31)

Definido o formato, passou-se para o desenvolvimento dos nomes de marca para um Posto de Combustíveis.

Os mesmos procedimentos descritos no Experimento 1 foram adotados para o desenvolvimento dos estímulos do Experimento 2. Após a realização dos processos de brainstorming, os tipos de nomes de marcas descritiva, sugestiva e arbitrária foram também expostos a diferentes grupos de estudantes para serem classificados, sendo os tipos de nomes de marcas com as maiores médias.

Para o nome de marca descritiva, Gasolina\&Companhia $(M=5,62 ; \mathrm{dp}=3,34)$ teve a melhor adequação. Para o nome de marca sugestiva, Tanque Cheio $(\mathrm{M}=7,03 ; \mathrm{dp}=2,95)$ se apresentou como o mais bem avaliado; para o nome de marca arbitrária, Pacific $(M=5,15$; dp $=3,27)$ mostrou-se o mais adequado. 
Para a manipulação da similaridade percebida no Experimento 2, adotou-se processo semelhante ao utilizado no Experimento 1. O formato de serviço Lava Rápido $(\mathrm{M}=8,17$; $\mathrm{dp}=2,27)$ se mostrou o mais adequado para a similaridade alta e o serviço Livraria $(M=2,37 ; \mathrm{d} p=2,47)$ foi o mais adequado para a baixa similaridade em relação a um Posto de Combustíveis. O teste $t$ de Student para amostras pareadas demonstrou diferença significante ao nível de $1 \%$ entre a similaridade percebida em relação aos serviços Lava Rápido e Livraria $(\mathrm{t}(35)=8,810 ; \mathrm{p}<0,01)$.

Para manipulação da qualidade percebida, idealizou-se um texto contendo a descrição do tipo de serviço selecionado e, conforme descrito anteriormente, foram utilizadas as dimensôes da qualidade da Servqual para evidenciar a qualidade percebida da MM. Para que a redação do texto fosse adequada para o experimento, seu teor foi encaminhado por correio eletrônico para dez professores doutores em administração com linha de pesquisa em marketing. Eles foram convidados a classificar, em uma escala de dez pontos, a presença de cada uma das cinco dimensóes da qualidade percebida de serviços, sendo 1 - esta dimensão da qualidade não está presente no texto e 10 - certamente esta dimensão da qualidade está presente no texto. Dos dez professores doutores convidados a realizar a validação de conteúdo, oito responderam. As médias quanto à presença das dimensôes da qualidade percebida de serviços no texto foram: Aspectos Tangíveis $(\mathrm{n}=8 ; \mathrm{M}=$ 9,69; $d p=0,70)$, Segurança $(n=8 ; M=8,63$; $\mathrm{dp}=8,63)$, Confiabilidade $(\mathrm{n}=8 ; \mathrm{M}=8,25 ; \mathrm{dp}$ $=1,67)$, Presteza $(n=8 ; M=7,64 ; d p=1,94)$ e Empatia ( $\mathrm{n}=8 ; \mathrm{M}=7,75 ; \mathrm{dp}=2,92)$. A operacionalização dessa manipulação, que resultou na elaboração de 12 questionários diferentes, é apresentada no Apêndice 3. Para a qualidade percebida baixa, foi utilizado um texto semelhante ao utilizado no Experimento 1.

\subsection{Amostra e procedimentos de controle do experimento 2}

A distribuição dos questionários foi realizada nas mesmas nove lojas utilizadas no Experimento 1 pelos mesmos pesquisadores treinados por um dos autores deste estudo. Contudo, como houve perda de 7\% dos questionários no primeiro experimento, os pesquisadores foram orientados a descartar os questionários deixados em branco ou com missing values, considerados inválidos. Após a finalização da coleta dos dados, apenas um formulário foi descartado pois o respondente assinalou duas alternativas simultaneamente em um dos itens da avaliação da extensão de marca.

A amostra final do Experimento 2 foi de 599 respondentes, sendo composta por 305 respondentes do sexo masculino $(50,9 \%)$ e 294 do sexo feminino (49,1\%), com idade média de 31 anos $(\mathrm{dp}=9,36)$.

\subsection{Resultados do experimento 2}

Iniciou-se a checagem da eficiência das manipulaçóes com o teste Qui-quadrado $(\chi 2=$ 181,513/12 g.l.; $\mathrm{p}<0,01)$, que demonstrou a eficiência na manipulação dos nomes de marcas. Referente à verificação da eficiência da manipulação da similaridade percebida, o teste $t\left(\mathrm{M}_{\text {similaridade }}\right.$ Baixa $=2,92 ; \mathrm{dp}=2,04 \mathrm{e} \mathrm{M}_{\text {similaridade Alta }}=4,26 ; \mathrm{dp}=$ $2,06 ; \mathrm{t}(595)=7.964 ; \mathrm{p}<0,01)$ indicou haver diferença significante na percepção da similaridade entre os formatos. A manipulação da qualidade percebida da MM também teve êxito, de acordo com o teste $t\left(\mathrm{M}_{\text {Qualidade Alta }}=4,60 ; \mathrm{dp}=1,84 \mathrm{e}\right.$ $\mathrm{M}_{\text {Qualidade Baixa }}=3,91 ; \mathrm{dp}=1,93 ; \mathrm{t}(595)=4.453$; $\mathrm{p}<0,01)$, que indicou haver diferença significante na percepção da manipulação da qualidade.

Seguiu-se com a AFE, que foi realizada com rotação não ortogonal oblíqua e análise de componentes principais. Da mesma maneira que correu no Experimento 1, a análise apontou para a bidimensionalidade dos itens das variáveis dependentes. Os Alfas de Cronbach para os itens de atitude $(0,911)$ e de intenção de uso $(0,786)$ garantiram a consistência dos fatores. As cargas fatoriais foram adequadas sendo superiores a 0,60 e cargas cruzadas (entre fatores) inferiores a 0,35. Da mesma maneira, o KMO $(0,929)$ apontou que a amostra é adequada para utilização da técnica de AFE (HAIR et al., 2005; FIELD, 2009). A Manova identificou efeito principal da similaridade percebida com intenção de uso $(\mathrm{F}(1,593)=3,085 ; \mathrm{p}<0,10)$ e da qualidade percebida com atitude $(\mathrm{F}(1,593)=$ 7,305; $\mathrm{p}<0,01)$. Os resultados encontrados são demonstrados nos Gráficos 3, 4, 5 e 6. 


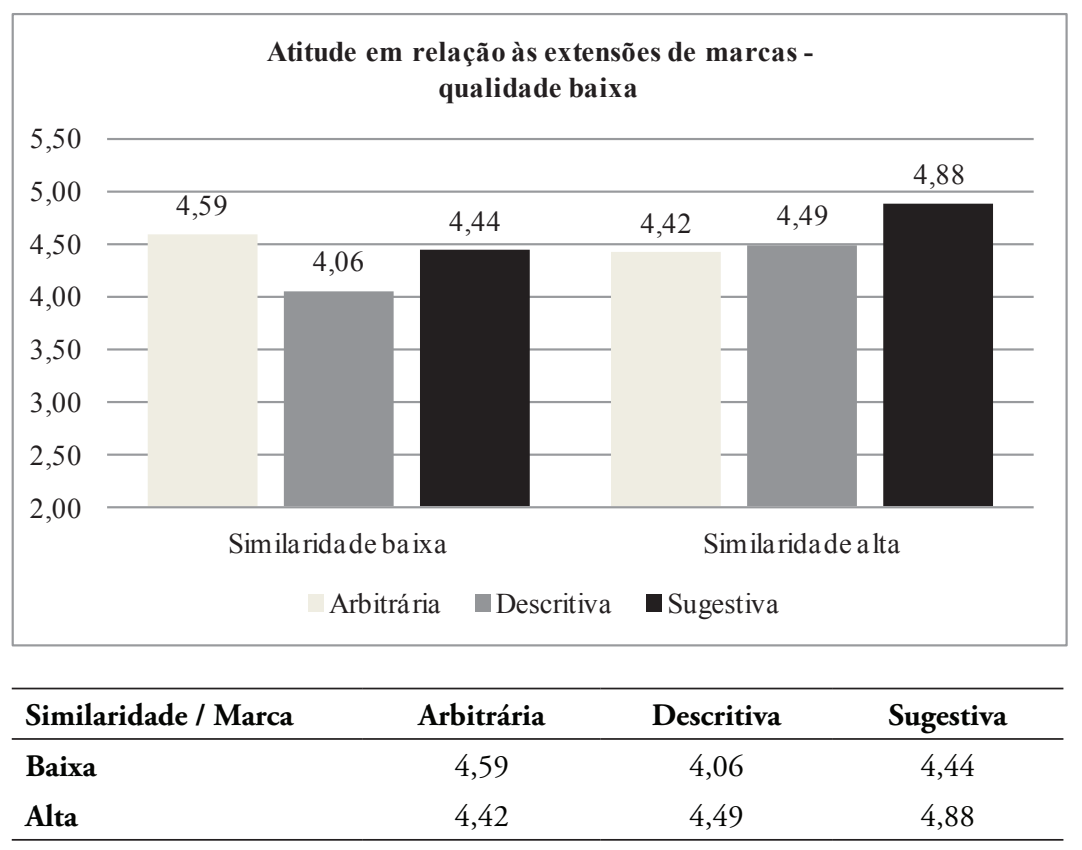

GRÁFICO 3 - Experimento 2 - atitude em relação às extensôes - qualidade baixa

Fonte: Dados da pesquisa, elaborado pelos autores.

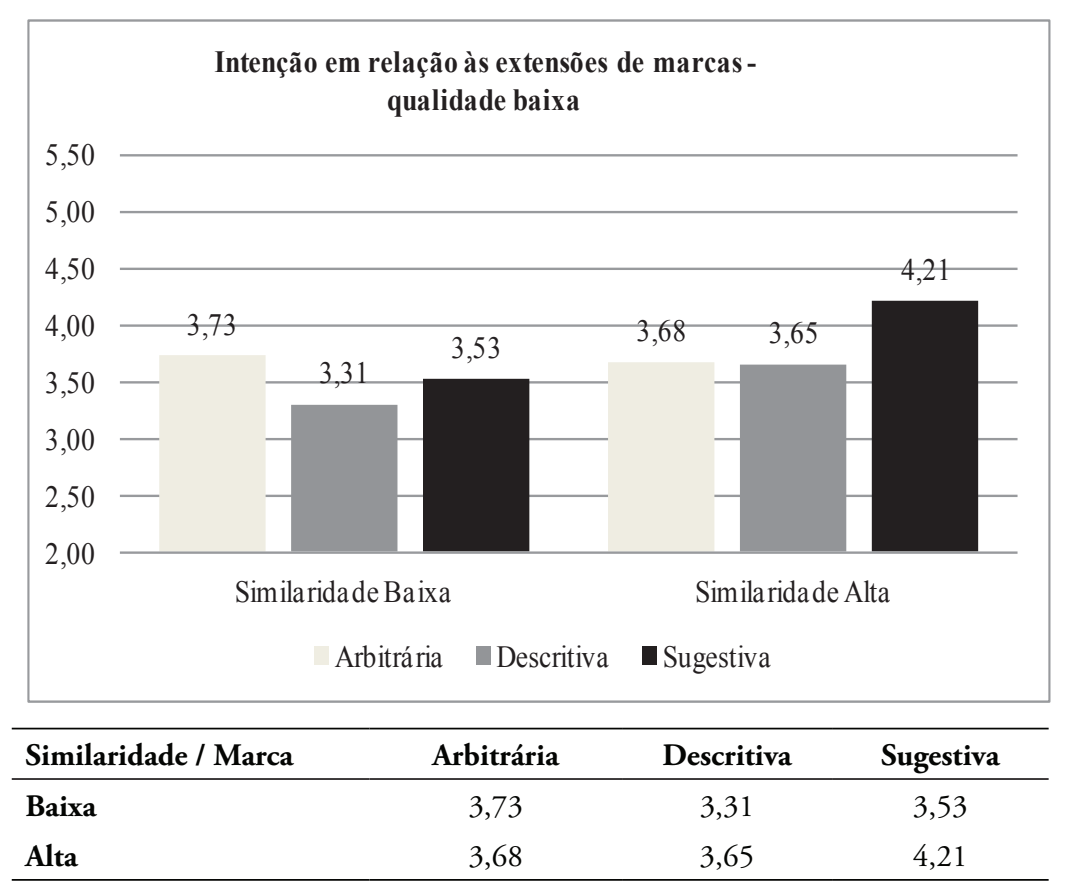

GRÁFICO 4 - Experimento 2 - intenção em relação às extensões - qualidade baixa

Fonte: Dados da pesquisa, elaborado pelos autores.

A análise apontou diferença significante nas relaçôes entre as marcas arbitrária e sugestiva com percepção de similaridade alta e qualidade baixa na atitude dos respondentes $\left(\mathrm{M}_{\text {Arbitrária }}=\right.$ 4,42 e $\left.\mathrm{M}_{\text {Sugestiva; }}=4,88 ; \mathrm{t}(97)=1,721 ; \mathrm{p}<0,10\right)$, tendo sido a marca sugestiva mais bem avaliada 
que a arbitrária, como já se esperava. A mesma diferença foi encontrada entre as marcas arbitrária e descritiva com percepção de similaridade baixa e qualidade baixa $\left(\mathrm{M}_{\text {Arbitrária }}=4,59\right.$ e $\mathrm{M}_{\text {Descritiva }}=$ $4,06 ; \mathrm{t}(96)=1,728 ; \mathrm{p}<0,10)$ e observou-se que a marca arbitrária foi mais bem avaliada que a marca descritiva.

Quanto à intenção de uso dos respondentes em relação às extensóes de marcas, observou-se diferença significante entre as marcas arbitrária e sugestiva com percepção de similaridade alta e qualidade baixa $\left(\mathrm{M}_{\text {Arbitrária }}=3,68\right.$ e $\mathrm{M}_{\text {Sugestiva }} 4,21$; $\mathrm{t}(97)=1,830 ; \mathrm{p}<0,10)$, sendo a marca sugestiva mais bem avaliada que a arbitrária, da mesma maneira que ocorreu na atitude, observadas as mesmas condiçôes. Verificou-se, ainda, diferença significante entre as marcas descritiva e sugestiva com percepção de similaridade alta e percepção de qualidade baixa $\left(\mathrm{M}_{\text {Descritiva }}=3,65\right.$ e $\mathrm{M}_{\text {Sugestiva }}=4,21$; $\mathrm{t}(96)=1,790 ; \mathrm{p}<0,10)$, sendo a marca sugestiva mais bem avaliada que a descritiva.

Houve diferença significante entre as médias atribuídas para a marca sugestiva com variação da percepção de similaridade (alta versus baixa). A marca sugestiva foi mais bem avaliada quando a percepção da similaridade foi alta, mantidas as condiçôes de percepção de qualidade baixa na intenção de uso dos respondentes em relação às extensões de marcas em serviços ( $\mathrm{M}$ $=3,53$ e $M_{\text {Sugestiva Similaridade baixa; }}=4,21 ; \mathrm{F}(1,98)=$ 5,325; $\mathrm{p}<0,05)$.

O Gráfico 5 apresenta as avaliaçóes referentes à atitude dos respondentes em relação às extensôes com percepção de qualidade alta. Foi observado que nenhuma das comparaçôes entre as médias apresentou diferença significante.

O Gráfico 6 apresenta os resultados da intenção de uso dos respondentes em relação às extensões com a percepção de qualidade alta. Observou-se que os efeitos da qualidade percebida da MM se mostraram relevantes também quanto à intenção de uso dos respondentes. Nenhuma das comparaçôes apresentou diferença significante quando a percepção de qualidade foi alta, da mesma maneira que ocorreu com a atitude.

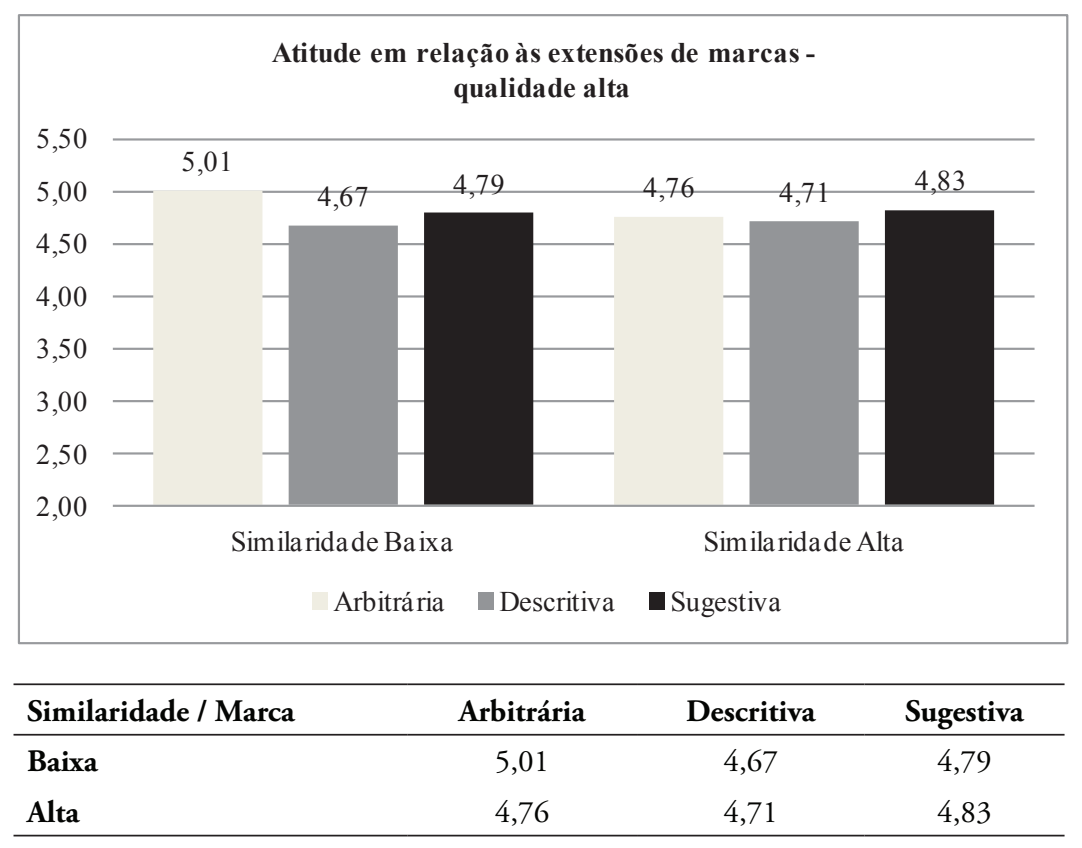

GRÁFICO 5 - Experimento 2 - atitude em relação às extensôes - qualidade alta

Fonte: Dados da pesquisa, elaborado pelos autores. 


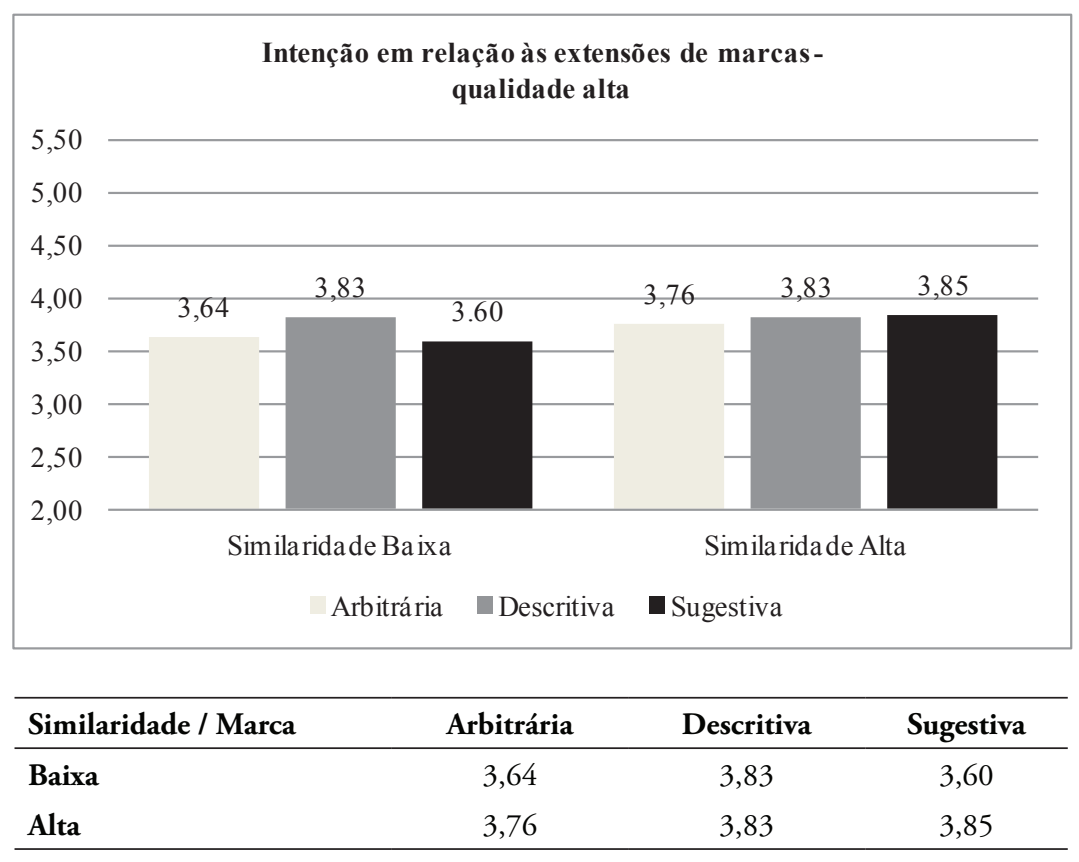

GRÁFICO 6 - Experimento 2 - intenção em relação às extensões - qualidade alta

Fonte: Dados da pesquisa, elaborado pelos autores.

\subsection{Discussáo dos resultados do experimento 2}

Os resultados encontrados apontam que o efeito da qualidade percebida da MM interfere na avaliação dos consumidores a respeito das extensôes, tanto na atitude quanto na intenção de uso. A influência direta da qualidade percebida na avaliação de extensôes tem sido observada em diversos estudos (SUNDIE, BRODIE, 1993; VAN RIEL, LEMMINK, OUWERSLOOT, 2001; ALLARD, VAN RIEL, OUWERSLOOT, 2005; MARTÍNEZ, PINA, 2005; LOPES, HERNANDEZ, 2010; HERNANDEZ et al., 2011) e, como dito anteriormente, uma percepção de maior qualidade na MM pode interferir na avaliação da extensão de marca, visto que pode ocorrer transferência da qualidade percebida para o novo produto ou serviço estendido.

Notou-se que, quando observadas as condições de percepção de similaridade e qualidade altas, não existiu diferença significante entre os nomes de marcas arbitrária e descritiva, diferentemente do que se previa. No entanto, quando a percepção de similaridade foi baixa, assim como a percepção de qualidade, verificou-se diferença significante entre as marcas arbitrária e descritiva, sendo a marca arbitrária mais bem avaliada do que a descritiva. Mesmo assim, a hipótese H4 foi rejeitada.

Ao se observar as condições de comparação da avaliação dos consumidores entre a marca sugestiva e a marca arbitrária em condições de percepção de similaridade baixa e qualidade baixa, verificou-se que, mesmo que exista uma tendência para uma melhor avaliação da marca arbitrária em comparação com a marca sugestiva e que nomes de marca sugestivas podem apresentar restriçóes quando a extensão de marca ocorre para formatos de baixa similaridade percebida (KELLER, HEKLER, HAUSTON, 1998), não ocorreu diferença significante entre as marcas. Da mesma maneira, também não ocorreu diferença quando comparadas as marcas sugestiva e arbitrária com percepção de similaridade alta e qualidade percebida alta. Fica, portanto, rejeitada a hipótese H5 e evidente a relevância dos efeitos da manipulação da qualidade se sobrepondo às demais variáveis manipuladas nesse experimento. 
A hipótese $\mathrm{H} 6$ propôs que a marca sugestiva seria mais bem avaliada que uma marca descritiva, quando a similaridade percebida da extensão fosse alta e a qualidade percebida da MM também o fosse. No entanto, observou-se a não existência de diferença significante entre as avaliações atribuídas pelos respondentes nas condições descritas, diferentemente do que se previa. Também não foi observada diferença significante entre as marcas sugestiva e descritiva, com percepção de similaridade baixa e percepção de qualidade baixa. Portanto, rejeitou-se também a H6.

Conforme comentado anteriormente, a literatura de marketing aponta a similaridade percebida da extensão para com a MM e a qualidade percebida da MM como os principais determinantes para uma boa avaliação das extensóes de marcas (BOTTOMLEY, HOLDEN, 2001; VÖLCKNER, SATTLER, 2006). Ao se observar os resultados obtidos nas comparaçóes das marcas descritiva e sugestiva com percepção de similaridade baixa e qualidade percebida alta, esperava-se que a marca sugestiva fosse mais bem avaliada que a descritiva, como proposto na hipótese H7. No entanto, foi verificado que não existiu diferença significante entre as marcas, rejeitando-se, portanto, a H7. Por outro lado, quando a percepção de similaridade do serviço estendido foi alta em relação ao serviço da MM e a qualidade percebida foi baixa, a marca sugestiva foi mais bem avaliada que a marca descritiva na intenção de uso dos respondentes no que se refere à extensão de marca. Também foi mais bem avaliada que a marca arbitrária tanto na atitude quanto na intenção de uso dos sujeitos da amostra a respeito das extensóes de marcas em serviços. Diante disso, aceitou-se a hipótese H8.

A marca sugestiva, como já se previa, foi mais bem avaliada em condiçóes de similaridade alta e percepção de qualidade baixa, quando comparada com as condiçôes de similaridade baixa e mantidas as condições de percepção de qualidade baixa. Os resultados apontaram que não existiu diferença significante entre as marcas arbitrária e descritiva em condiçôes de similaridade baixa do serviço estendido e qualidade percebida alta. Assim, rejeita-se a hipótese H9.
Percebeu-se, com os resultados do Experimento 2, que, quando ocorreu percepção de qualidade alta, os efeitos dos nomes de marca (arbitrária, descritiva e sugestiva) e da similaridade (alta versus baixa) foram anulados. Os respondentes, diante de uma percepçáo de alta qualidade, avaliaram as extensões de marcas em serviços sem levar em conta os nomes e a similaridade. Tais evidências colaboram com os achados dos estudos de Völckner et al. (2010) e Hernandez et al. (2011).

Deve-se destacar, aqui, que os efeitos verificados estão em um contexto de marcas não reconhecidas, pois todas as marcas utilizadas foram desenvolvidas para os Experimentos $1 \mathrm{e}$ 2 , conforme descrito nos itens que trataram do desenvolvimento dos estímulos. Portanto, as avaliaçôes dos consumidores poderiam diferir diante da manipulação de marcas reconhecidas.

\section{DISCUSSÃO GERAL DOS RESULTADOS}

Estimulado pela carência de pesquisas sobre extensão de marcas em serviços na literatura de marketing, este estudo teve como objetivo analisar os efeitos de tipos de nomes de marca (arbitrária, descritiva e sugestiva), manipulados juntamente com a percepção de similaridade (alta versus baixa) e a percepção de qualidade da MM (alta versus baixa), nas avaliaçóes dos consumidores, a respeito de extensóes de marcas em serviços.

Por meio da aplicação de questionários estruturados, 460 indivíduos foram convidados a desenvolver os estímulos utilizados nos experimentos e 878 consumidores, a avaliar as extensôes de marcas em serviços, totalizando, portanto, um total de 1.338 sujeitos. No Experimento 1, com os resultados encontrados, percebeu-se que o consumidor tende a apresentar determinada destreza na interpretação a respeito da marca quando ela facilita a ligação do serviço com seus atributos ou benefícios. Essa aplicação valida estudos realizados que envolveram manipulação de nomes de marcas (MOORE, LEHMANN, 1982; LOPES, HERNANDEZ, 2010) e de similaridade percebida da extensão para com a MM (HERNANDEZ et al., 2011; NEERAKKAL, 2011). 
No Experimento 2, acrescentou-se a manipulação da qualidade percebida da MM. A presença das dimensóes da qualidade de serviços nos estímulos criados para o Experimento 2 fizeram que as extensôes fossem avaliadas levando em consideração apenas a qualidade percebida.

De modo geral, os resultados encontrados nesta pesquisa indicam que a similaridade da extensão de marca em serviços perante a MM apresenta efeitos significantes nas avaliaçóes dos consumidores tanto na atitude quanto na intenção de uso.

Quanto aos nomes, notou-se que a extensão de marca com nome de marca arbitrária em serviços é mais bem avaliada quando a similaridade da extensão é baixa. E a extensão de marca com nome de marca descritiva ou sugestiva em serviços é mais bem avaliada quando a similaridade da extensão é alta, apresentando efeitos significantes tanto na atitude quanto na intenção de uso dos consumidores. Quando se manipulou a qualidade percebida da MM, constatou-se que ocorreu a transferência desta para a extensão de marca em serviços, tanto nos casos com similaridade percebida alta quanto baixa. Os efeitos da percepção de alta qualidade da MM se sobrepóem aos efeitos da similaridade (alta versus baixa) e dos nomes de marcas nas extensões de marcas em serviços, tanto na atitude quanto na intenção de uso dos consumidores. A Tabela 1 apresenta o resultado do teste das hipóteses.

TABELA 1 - Teste das hipóteses

\begin{tabular}{cccccc}
\hline Hipóteses & Conclusáo & Hipóteses & Conclusáo & Hipóteses & Conclusáo \\
\hline H1 & Não rejeitada & H4 & Rejeitada & H7 & Rejeitada \\
H2 & Rejeitada parcialmente & H5 & Rejeitada & H8 & Não rejeitada \\
H3 & Rejeitada parcialmente & H6 & Rejeitada & H9 & Rejeitada \\
\hline
\end{tabular}

Fonte: Dados da pesquisa, elaborado pelos autores.

Grande parte das hipóteses testadas foi rejeitada, pois a percepção de alta qualidade dos serviços da MM anularam os efeitos das MEs na avaliação dos consumidores. Ainda que as marcas não reconhecidas tenham sido usadas nos experimentos, observou-se transferência de qualidade percebida da MM para a extensão de marca em serviços, resultado diferente do encontrado por Aaker e Keller (1990) em extensóes de produtos tangíveis e também distintos dos encontrados por Pina et al. (2006) e Völckner et al. (2010) em extensões de marcas em serviços. Com isto, acredita-se que um novo gap foi identificado: a qualidade percebida da MM pode influenciar a avaliação da $\mathrm{ME}$ em contextos específicos, como no caso de serviços puros.

Ainda sobre os efeitos da qualidade percebida nas avaliações das extensôes de marcas em serviços, os resultados encontrados se assemelham aos de Hernandez et al. (2011), que demonstraram que serviços que possuem alta qualidade percebida têm maior probabilidade de lançar extensôes de marca bem sucedidas. Tais estudos, porém, não manipularam tipos de nomes de marca, como foi realizado neste estudo. Espera-se, portanto, que esse esforço, no sentido de compreender melhor como os consumidores percebem e avaliam as extensões de marcas em serviços, possa servir de base para novas pesquisas na mesma linha.

\section{I Implicaçóes gerenciais}

Como os resultados demonstraram, nomes de marca arbitrária podem apresentar melhor aceitação em extensôes de baixa similaridade, ao passo que nomes de marcas sugestivas ou descritivas podem apresentar melhor aceitação em extensóes de marca com alta similaridade, quando não se observa alta qualidade percebida. Por exemplo, a extensão de marca em condiçôes de baixa similaridade entre a MM e a ME tende a ser favorecida quando a marca é arbitrária, pois, nesse estudo, a extensão da marca Supermercado Ambra foi mais positiva que as demais quando 
utilizada em uma Agência de Turismo. Por outro lado, a extensão da MM para a ME em condiçóes de alta similaridade percebida tende a ser mais bem avaliada quando a MM é sugestiva (nessa aplicação a extensão do Supermercado Leve Mais para o Restaurante Leve Mais).

De maneira geral, os profissionais de marketing que lidam com marcas no setor de serviços, em um contexto de marcas não reconhecidas, devem se dedicar a fazer que suas marcas de serviços apresentem alta percepção de qualidade, pois ficou retratado pelos resultados observados que a percepçáo de qualidade alta se sobrepóe aos efeitos dos nomes de marcas e da similaridade percebida nas avaliaçóes das extensóes de marcas em serviços.

\section{$5 \cdot 2$ Limitaçóes da pesquisa e sugestóes para estudos futuros}

Por se tratar de uma pesquisa experimental, mesmo tomados vários cuidados na elaboração dos estímulos e em sua manipulação, admite-se que o efeito dos estímulos pode não ter sido interpretado igualmente pelos participantes do experimento, afetando sua validade interna. Para mitigar esse limite, sugere-se a replicação desse estudo como forma de validar seus achados.

Outra limitação foi a não utilização de nomes de marcas reais e reconhecidas. Abre-se aqui a possibilidade de novas replicaçóes com o uso de marcas reconhecidas pelos consumidores e posterior manipulação (ou mensuração) da qualidade percebida nesses casos. Com isso, haveria confirmação da validade interna dos experimentos e maior validade externa de seus resultados.

A característica não probabilística da amostra foi outro limite identificado. Mesmo que sejam muito utilizadas em pesquisas experimentais (LOPES, HERNANDEZ, 2010), em razão, principalmente, das restrições orçamentárias e de tempo para realização dos estudos acadêmicos (HAIR et al., 2005), essa característica impede a generalização dos resultados para o universo.

Uma limitação inerente ao método adotado é a falta de comparabilidade do comportamento das variáveis por meio da observação de um grupo de controle. Mesmo que a falta de um grupo de controle náo invalide os resultados encontrados, sua inclusão daria mais força a eles. Sob esse aspecto, sugere-se que as próximas iniciativas no avanço do estudo deste tema incluam grupos de controle em seus desenhos experimentais.

Sugere-se que pesquisas futuras tratem da investigação, não apenas das variáveis envolvidas neste estudo, mas também de outras, como a manipulação de formatos de serviços e marcas que envolvam canais eletrônicos, a fim de verificar se os resultados encontrados apresentam validade diante de novos canais de prestação de serviços. Recomenda-se, também, a manipulação de marcas reconhecidas, conforme dito anteriormente, e a realização de estudos para mensurar os efeitos do apego emocional e do envolvimento do consumidor diante de estratégias de extensóes de marcas em serviços.

* Os autores agradecem sinceramente por todas as sugestôes de melhoria realizadas pelos avaliadores anônimos deste periódico.

\section{REFERÊNCIAS}

AAKER, D. A. Marcas: brand equity gerenciando o valor da marca. Sáo Paulo: Negócio, 1998.

; KELLER, K. L. Consumer evaluations of brand extensions. Journal of Marketing, Chicago, v. 54, n. 1, p. 27-51, Jan. 1990.

ALLARD, C. R; VAN RIEL, A.; OUWERSLOOT, H. Extending electronic portals with new services. Journal of Retailing and Consumer Services, [S. 1.], v. 12, 4, 245-254, July 2005.

AMERICAN MARKETING ASSOCIATION (AMA). c2014. Disponível em: < https://www. ama.org/Pages/default.aspx >. Acesso em: 25 jun. 2014.

BATRA, R.; LENK, P.; WEDEL, M. Brand extension strategy planning: empirical estimation of brand-category personality fit and atypicality. 
Journal of Marketing Research, [S. 1.], v. 47, n. 2, p. 335-347, Apr. 2010.

BOTTOMLEY, P. A.; HOLDEN, S. J. S. Do we really know how consumers evaluate brand extensions? Empirical generalizations based on secondary analysis of eight studies. Journal of Marketing Research, [S. 1.], v. 38, n. 4, p. 494500, Nov. 2001.

BOUSH, D. M.; LOKEN, B. A process tracing study of brand extension evaluation. Journal of Marketing Research, [S. 1.], v. 28, n. 1, p. 16-28, Feb. 1991.

CRONIN, J.; TAYLOR, S. Measuring service quality: a reexamination and extension. Journal of Marketing, Chicago, v. 56, n. 3, p. 55-68, July 1992.

FIELD, A. Descobrindo a estatística usando o SPSS. 2. ed. Porto Alegre: Artmed, 2009.

HAIR, J. F. et al. Análise multivariada de dados. 5. ed. Porto Alegre: Bookman, 2005.

HERNANDEZ, J. M. C. et al. Extensão de marcas corporativas de serviços: o efeito da similaridade percebida da extensão e da qualidade percebida da marca. RAC - Revista de Administração Contemporânea. Curitiba, v. 15, n. 4, p. 561-579, jul./ago. 2011.

KELLER, K. L. Strategic brand management: building, measuring, and managing brand equity. New York: Prentice Hall, 2003.

; AAKER, D. A. The effects of sequential introduction of brand extensions. Journal of Marketing Research, [S. 1], v. 29, n. 1, p. 35-50, Feb. 1992.

; HECKLER, S.; HAUSTON, M. J. The effects of brand name suggestiveness on advertising recall. Journal of Marketing, Chicago, v. 62, n. 1, p. 48-57, Jan. 1998.

; MACHADO, M. Gestão estratégica de marcas. São Paulo: Pearson Prentice Hall, 2006.
LEE, H.; LEE, Y.; YOO, D. The determinants of perceived service quality and its relationship with satisfaction. Journal of Services Marketing, Bradford, n. 14, n. 3, p. 217-31, 2000.

LEI, J. et al. Service intensiveness and brand extension evaluations. Journal of Service Research, Bradford, v. 6, n. 3, p. 243-255, Feb. 2004.

LOPES, E. L.; HERNANDEZ, J. M. C. Percepção da estratégia de extensão de marca em estabelecimentos comerciais: qual o melhor nome para uma loja? In: IV Encontro de Marketing (EMA) da ANPAD. 5, 2010, Florianopólis. Anais eletrônico... Florianópolis: ANPAD, 2010. Disponível em: <http://www.anpad.org.br/diversos/ trabalhos/EMA/ema_2010/2010_EMA355. pdf>. Acesso em: 10 set. 2012.

; NOHARA, J. J. Escalas concorentes para a mensuração da qualidade percebida: uma comparação entre a Servqual ea RSQ. RAE - Revista de Administração de Empresas, São Paulo, v. 49, n. 4, p. 401-416, out./dez. 2009.

MARTÍNEZ, E.; PINA, J. M. Influence of corporate image on brand extensions: a model applied to the service sector. Journal of Marketing Communications. London, v. 11, n. 4, p. 263-281, 2005.

MOORE, W. L.; LEHMANN, D. R. Effects of usage and name on perceptions of new products. Marketing Science, Linthicum, v. 1, n. 4, p. 351-370, Nov. 1982.

MORRIN, M. The impact of brand extensions on parent brand memory structures and retrieval processes. Journal of Marketing Research, [S. l], v. 36, n.4, p. 517-525, Nov. 1999.

NEERAKKAL, J. A. Consumer evaluations of product line brand extension. The IUP Journal of Brand Managemente, [S. 1.], v. 8, n. 1, 22-35, Mar. 2011.

OLIVEIRA, B. A. C. de; MATTAR, F. N. Um estudo acerca das estratégias de extensōes de marca e de linha de produtos. RAM - Revista 
de Administração Mackenzie, São Paulo, v. 2, n. 1, 39-54, 2001.

PARASURAMAN, A.; ZEITHAML V. A.; BERRY, L. L. Delivering quality service. Balancing customer perceptions and expectations. New York: The Free Press, 1990.

PINA, J. M. et al. The effect of service brand extensions on corporate image: an empirical model. European Journal of Marketing, [S. 1.], v. 40, n.1/2, p. 174-197, 2006.

RUYTER, K.; WETZELS, M. The role of corporate image and extension similarity in service brand extensions. Journal of Economic Psychology, Amsterdam , v. 21, n. 6, p. 639-659, Dec. 2000.

SHEERAN, P.; HARRIS, P.R.; EPTON, T,. Does heightening risk appraisals change people's intentions and behavior? A meta-analysis of experimental studies. Psychological Bulletin, Washington, D.C, v. 140, n. 2, p. 511, Mar. 2014.

SMITH, D. C. Brand extension and advertising efficiency: what can and cannot be expected. Journal of Advertising Research, New York, v.32, n. 6, p. 11-20, Nov. 1992.

; PARK, C. W. The effects of brand extensions on market share and advertising efficiency,
Journal of Marketing Research, [S. 1.], v. 29, 296-313, Aug. 1992.

SULLIVAN, M. W. Brand extensions: when to use them. Management Science, Linthicum, v. 38, n. 6, jun., p. 793-806, June 1992.

SUNDIE, L.; BRODIE, R. J. Consumer evaluations of brand extensions: Further empirical results . International Journal of Research in Marketing, Amsterdam, v. 10, n. 1, p. 47-53, Mar. 1993.

VAN RIEL, A. C. R.; LEMMINK, J.; OUWERSLOOT, H. Consumer evaluation of service brand extensions, Journal of Service Research, Thousand Oaks, v. 3, n. 3, p. 220-231, Feb. 2001.

; OUWERSLOOT, H. Extending electronic portals with new services: exploring the usefulness of brand extension models. Journal of Retailing and Consumer Services, [S. 1.], v. 12 , n. 4, p. 245-254, July 2005.

VÖLCKNER, F.; SATTLER, H. Drivers of brand extension success. Journal of Marketing, Chicago, v. 70, n. 2, p. 18-34, Apr. 2006.

.et al. The role of parent brand quality for service brand extension success. Journal of Service Research, Thousand Oaks, v. 13, n. 4, 379-396, June 2010. 
APÊNDICE A - Manipulação das variáveis do experimento 1

Prezado(a) consumidor(a),

Estamos assessorando uma Rede de Supermercados sediada em São Paulo, que atualmente possui um grande número de lojas. Trata-se do SUPERMERCADO <marca>. As lojas do SUPERMERCADO < marca $>$ oferecem variedade de produtos bastante adequada para sua clientela, contando com gêneros alimentícios, laticínios, carnes, pães, bebidas, hortifrúti e congelados, além de produtos de higiene, limpeza e beleza entre outros. Opera com qualidade e pratica preços justos. Mantém os produtos separados por categorias em prateleiras dispostas de maneira a oferecer espaço para circulação dos clientes em suas lojas, possui estacionamento e boa localização garantindo conveniência a todos os clientes.

Visando diversificar sua atuação no mercado, este varejista pretende abrir um(a) < RESTAURANTE / AGÊNCIA DE TURISMO > que se chamará < RESTAURANTE MARCA / AGÊNCIA DE TURISMO MARCA>.

[a] Na AGÊNCIA DE TURISMO <marca> você encontrará uma diversidade de escolhas de destinos para suas viagens em um ambiente bastante adequado. As unidades das AGÊNCIAS DE TURISMO <marca> serão bem localizadas e contarão com serviços comuns às agências de turismo do seu porte.

[ou b] No RESTAURANTE < marca> você poderá desfrutar de uma diversidade de pratos em um ambiente bastante adequado. As unidades do RESTAURANTE < marca> serão bem localizadas e contarão com serviços comuns aos restaurantes do seu porte.

Gostaríamos de saber sua opinião sobre o <RESTAURANTE MARCA / AGÊNCIA DE TURISMO MARCA >. Todas as respostas são estritamente confidenciais e serão analisadas apenas de maneira agregada. Leia as afirmativas a seguir e classifique-as atribuindo-lhes notas, sendo 1 - Discordo totalmente e 7 - Concordo totalmente. Caso sua resposta seja intermediária, pedimos que você assinale um dos números entre 2 e 6 . Não existem repostas certas ou erradas, apenas queremos saber a sua opinião sobre o(a) < RESTAURANTE MARCA / AGÊNCIA DE TURISMO MARCA >.

APÊNDICE B - Variáveis da escala de mensuração da avaliação das extensões de marca em serviços decomposta em atitude e intenção.

\begin{tabular}{|c|c|c|}
\hline Construto & Cód. & Afirmativa \\
\hline \multirow{8}{*}{ Atitude } & A1 & O(A) <FORMATO DO SERVIÇO + MARCA> será viável. \\
\hline & A2 & $\mathrm{O}(\mathrm{A})<$ FORMATO DO SERVIÇO + MARCA $>$ será excelente. \\
\hline & A3 & O(A) <FORMATO DO SERVIÇO + MARCA > será um sucesso. \\
\hline & A4 & $\mathrm{O}(\mathrm{A})<$ FORMATO DO SERVIÇO + MARCA> terá grande aceitação dos consumidores. \\
\hline & A5 & Sou muito favorável à inauguraçấo do(a) <FORMATO DO SERVIÇO + MARCA>. \\
\hline & A6 & Eu certamente recomendaria $\mathrm{o}(\mathrm{a})<$ FORMATO DO SERVIÇO + MARCA > para parentes e amigos. \\
\hline & A7 & Eu adoraria frequentar $\mathrm{o}(\mathrm{a})<$ FORMATO DO SERVIÇO + MARCA $>$. \\
\hline & A8 & Certamente consideraria muito interessante o(a) <FORMATO DO SERVIÇO + MARCA $>$. \\
\hline \multirow{4}{*}{ Intençáo } & I1 & $\begin{array}{l}\text { Eu seguramente frequentaria mais o(a) <FORMATO DO SERVIÇO + MARCA }>\text { do que os }(\mathrm{as})<\text { FORMA- } \\
\text { TO DO SERVIÇO > que frequento atualmente. }\end{array}$ \\
\hline & I2 & $\begin{array}{l}\text { Sem dúvida alguma, deixarei de ir ao(a) }<\text { FORMATO DO SERVIÇO }>\text { que frequento atualmente para } \\
\text { frequentar o(a) }<\text { FORMATO DO SERVIÇO + MARCA }>\text {. }\end{array}$ \\
\hline & I3 & $\begin{array}{l}\text { Eu certamente gastaria a maior parte do meu orçamento para }<\text { FORMATO DO SERVIÇO }>\text { no(a) }<\text { FOR- } \\
\text { MATO DO SERVIÇO + MARCA }>\text {. }\end{array}$ \\
\hline & 14 & $\begin{array}{l}\text { Definitivamente valerá a pena utilizar o(a) <FORMATO DO SERVIÇO + MARCA> em vez do(a) que } \\
\text { utilizo hoje, mesmo que os preços sejam iguais. }\end{array}$ \\
\hline
\end{tabular}


APÊNDICE C - Variáveis de checagem da manipulação dos estímulos

\begin{tabular}{|c|c|}
\hline Estímulo & Afirmativa \\
\hline Marca arbitrária & Eu certamente conheço a marca <NOME DE MARCA ARBITRÁRIA>. \\
\hline Marca descritiva & $\begin{array}{l}\text { A marca <NOME DE MARCA DESCRITIVA> certamente descreve os serviços prestados por um } \\
<\text { FORMATO DO SERVIÇO DA MARCA-MÃE >. }\end{array}$ \\
\hline Marca sugestiva & $\begin{array}{l}\text { A marca <NOME DE MARCA SUGESTIVA > certamente sugere benefícios dos serviços prestados por } \\
\text { um <FORMATO DO SERVIÇO DA MARCA-MÃE >. }\end{array}$ \\
\hline $\begin{array}{l}\text { Similaridade do serviço } \\
\text { estendido }\end{array}$ & $\begin{array}{l}\text { A atividade de um(a) <FORMATO DO SERVIÇO ESTENDIDO> é certamente muito similar à ativi- } \\
\text { dade de um <FORMATO DO SERVIÇO DA MARCA-MÃE >. }\end{array}$ \\
\hline Qualidade percebida & A qualidade do(a) <FORMATO DO SERVIÇO ESTENDIDO + NOME DE MARCA > é excelente. \\
\hline
\end{tabular}

APÊNDICE D - Manipulação das variáveis do experimento 2

\section{Prezado(a) consumidor(a),}

Estamos assessorando uma Rede de Postos de Combustíveis sediada em São Paulo, que atualmente possui um grande número de lojas. Trata-se da Rede de POSTOS DE COMBUSTÍVEIS < marca>. Os POSTOS < marca> possuem ótimas instalaçóes, os equipamentos para o abastecimento dos veículos são de última geração, a disposição das bombas de combustíveis possibilita ótima circulação para os consumidores e seus veículos. Os POSTOS < marca> contam com sistemas eficazes para garantir total segurança a todos os clientes quanto às formas de pagamento, evitando qualquer tipo de fraude. Os postos possuem circuito fechado de TV e oferecem também um canal de comunicação direto com sua gerência. Oferecem cartão de fidelização aos clientes e mantêm cadastros sempre atualizados, possibilitando ao cliente um atendimento personalizado. Mantêm sempre contato com os clientes para comunicar novos serviços e, cada vez mais, entender as preferências do seu público. Os colaboradores são orientados a dar atenção especial a todos os clientes, possuem treinamento para garantir total segurança ao manusear os produtos comercializados, além de serem treinados para situaçóes adversas. Os POSTOS <marca> possuem todas as licenças e certificaçóes exigidas para o seu funcionamento. Todos que trabalham nos POSTOS $<$ marca $>$ estão sempre uniformizados e possuem habilidades para realizar a prestação dos serviços com agilidade e excelência.

Visando diversificar sua atuação no mercado, este varejista pretende abrir um(a) <LAVA-RÁPIDO / LIVRARIA> que se chamará <LAVA-RÁPIDO MARCA / LIVRARIA MARCA>. Utilizando todo conhecimento nos serviços automotivos da rede de postos, pretende-se oferecer um serviço com a mesma qualidade que o cliente já está acostumado. Assim como os POSTOS DE COMBUSTÍVEIS, você sempre encontrará um(a) <LAVA-RÁPIDO MARCA / LIVRARIA MARCA> perto de você.

Gostaríamos de saber sua opinião sobre o(a) <LAVA-RÁPIDO MARCA / LIVRARIA MARCA>. Todas as respostas são estritamente confidenciais e serão analisadas apenas de maneira agregada. Leia as afirmativas a seguir e classifique-as atribuindo-lhes notas, sendo $\mathbf{1}$ - Discordo totalmente e 7 - Concordo totalmente. Caso sua resposta seja intermediária, pedimos que você assinale um dos números entre 2 e 6 . Não existem repostas certas ou erradas, apenas queremos saber a sua opinião sobre o(a) <LAVA-RÁPIDO MARCA / LIVRARIA MARCA>. 